\title{
Cite Globally, Analyze Locally: Citation Analysis from a Local Latin American Studies Perspective
}

\section{Suzanne M. Schadl and Marina Todeschini}

This citation analysis examines the use of Spanish- and Portugueselanguage books and articles in PhD dissertations on Latin America at the University of New Mexico between 2000 and 2009. Two sets of data are presented: The first identifies the use of Spanish- and Portugueselanguage books and articles across 17 academic departments; and the second analyzes how well local holdings meet demands for a select geographical area-Mexico. These local data contradict conclusions in general citation studies of the humanities, social sciences and foreign languages. They prove that preconceived ideas about foreign language usage from general citation studies do not provide reliable templates for local acquisition decisions. Librarians need to look at their research communities and local usage habits instead of relying on general studies for answers.

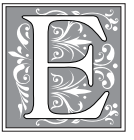

mphasis on Latin American research at the University of New Mexico (UNM) began in the 1930s under the stewardship of then-President James F. Zimmerman. He urged the state legislature to support Latin American activities and initiatives because, he stated, "the bonds which exist between us [New Mexico] and our neighbors to the south are not only geographic, but linguistic and cultural..." ${ }^{1}$ This distinction culminated in 1979 when, after several decades of success in Latin American studies, UNM inaugurated the Latin American \& Iberian Institute (LAII). Today, this state flagship university is a U.S. Department of Education Title VI recipient, awarded federal funding for Foreign Language and Area Studies (FLAS). UNM's Latin American library collections have supported FLAS research and achieved acclaim over the decades. They are currently recognized among the top in the nation. This distinction enables UNM to be a prominent player in shared collection development, preservation, and consortia. The library is particularly engaged with the Seminar for the Acquisitions of Latin American Library Materials (SALALM), which promotes cooperative efforts to achieve better library services for Latin Americanist scholars and purchasing power for bibliographers and subject selectors in the field.

As an institutional member of SALALM, UNM participates in shared preservation initiatives and distributed resources projects, such as LAMP (formerly known as the

Suzanne M. Schadl is Latin American Collections Curator, University Libraries, and Marina Todeschini is a Graduate Research Fellow, Inter American Studies and the Latin American Iberian Institute, at the University of New Mexico; e-mail: schadl@unm.edu, marinat@unm.edu. (c) 2015 Suzanne M. Schadl and Marina Todeschini, Attribution-NonCommercial (http://creativecommons.org/licenses/by-nc/3.0/) CC BY-NC. 
Latin American Microform Project) and the Latin Americanist Research Resources Project (LARRP). Under the umbrella of the Center for Research Libraries, these important multi-institutional shared collection development projects facilitate cooperation among major repositories of Latin American materials in the United States and Latin America. Less formalized than regional consortia such as the Greater Western Library Alliance (GWLA), in which UNM stands out as a net lender of Latin American materials, LAMP and LARRP have addressed collaborative collection strategies for several decades. ${ }^{2}$ These collaborative approaches are essential as federal funding, for FLAS continues to diminish in our current economy.

Added to pressures associated with financial woes are tenuous discussions of how the changing roles of libraries impact research collections, and with good reason. Books, articles, archival materials and data sets are digitally available via Google, Yahoo, and Bing searches. Augmented demands for database resources, electronic books, digital objects, and expensive packages make priorities for physical library sources increasingly less feasible. It is important, however, to look carefully at graduate-level usage before making assumptions about value, especially in areas where well-established research strengths reflect unique institutional strengths. While some data may support the idea that electronic resources offer more bang for the buck, it is important to quantify graduate student citations. Thoughtful decisions must extend beyond generalized statistics and look at the peculiarities of local research in various disciplines.

This article analyzes the actual research usage of Spanish- and Portuguese-language books and articles at UNM for several purposes: to determine which academic departments use Spanish- and Portuguese-language materials; to gather data for collection development decisions; to measure the broad impact of these foreign language materials on the research mission of the university; and to justify continued support for these historic collections. The first set of data presented in this article employs basic bibliometrics to examine Spanish- and Portuguese-language secondary source citations across PhD-granting departments at UNM from 2000 to 2009. These data are useful for ascertaining the extent to which graduate students in varying departments use foreign language materials. However, they fail to indicate how well local collections meet graduate-level research needs, indicating little about the effectiveness of past acquisitions. A second set of data assesses the library's holdings of titles cited in dissertations on Mexico. Due to the time-consuming nature of a comprehensive study for each Latin American country, the data focus on Mexico, the library's most comprehensive collection.

\section{Latin American Acquisitions at the University of New Mexico}

Spanish- and Portuguese-language monographs and journals published in Latin America represent the strongest single area of UNM's library collections, comprising over 25 percent of monograph holdings. According to the 2010-2011 SALALM survey, the UNM Library ranks third among reporting institutions in expenditures on Latin American materials and fourth in terms of its collections. ${ }^{3}$ These foreign language materials have long enjoyed prioritization at UNM, and they remain an important emphasis in collection development. UNM's faculty handbook recognizes this area of institutional strength and encourages Latin American research across campus. Spanish- and Portuguese-language materials support advanced-level graduate work on Latin American topics in many departments. Even so, questions about the value of these sources have emerged, largely because of a misconception that they serve only researchers in Latin American Studies and the Department of Spanish and Portuguese.

The library allocates upwards of 11 percent of the acquisitions budget to materials published in Latin America. Roughly half of that expenditure goes to books. The rest 
is spent among serial subscriptions, databases, electronic books, and archival acquisitions. Nearly a third of these purchases come from Mexico. A closer look at those Mexican sources reveals that art history and architecture comprise approximately 40 percent of the Mexican expenditures. The next highest investments come in Mexican literature (12 percent), history, geography and anthropology (each at 10 percent). It is important to note that art and architecture books cost two to five times more than novels and academic monographs, so a greater expenditure in these subjects does not mean the library acquires more books in these fields. Holdings for Mexican history and literature at UNM actually outweigh those in these areas as well as in other subjects.

\section{Literature Review}

Lewis Hanke and others note that Latin American studies began in the early twentieth century with the exchange of scholars between the United States and Latin America. ${ }^{4}$ Institutional efforts to build repositories of materials from the region followed and facilitated the establishment of FLAS programs and library collections. These initiatives enable scholars from different countries and academic disciplines to converge around diverse studies of specific geographic regions. David L. Szanton, citing Alan Tansman, cogently presents area studies as broad-scale translations of other cultures' assumptions, structures, and dynamics. Such interpretations require multiple sources from the region to share, "capture," and "convey" understandings of other societies. Area studies librarianship supports these requirements by ensuring the availability of foreign language sources.

Lynn Shirey sums up the difficulty of defining area studies librarianship. She notes that Latin American studies encompass multiple subjects, making simplification difficult. She also correctly states that some Latin American collections focus on Latin America as a geographically defined publishing area, collecting all subject fields from the region; while other institutions define these collections in terms of academic fields, directing their attention to respective scholarly works from various countries on Latin America. ${ }^{6}$ Generally speaking, research libraries with a heavy emphasis in area studies and foreign languages combine these approaches to better facilitate access to diverse perspectives and scholarly exchange between publications in the United States and Latin America.

By bringing together scholars around foreign resources, area studies create diversified subcommunities for the promotion of new and often multinational and multidisciplinary perspectives. Though bibliographers were among the first to contribute to Latin American studies, librarians have been more focused on building collections than on understanding how those collections interact with their academic communities. In Building Area Studies Collections, Dan C. Hazen and James H. Spohrer offer important information on publishing industries, international scholarly communications, broadreaching bibliographic tools, cooperative collection arrangements, and librarian/vendor relationships. ${ }^{7}$ However, their focus on the supply-side of area studies librarianship is a limitation; it overlooks the necessity to better rationalize research collections with actual usage.

Orchid Mazurkiewicz and Claude Potts' survey of student members of the Latin American Studies Association offers some insight for rationalizing collections. Their conclusions suggest that students prefer traditional materials like books and journal articles, and they employ traditional research methods like shelf-browsing, resourcesharing and following bibliographic citations. Mazurkiewicz and Potts' sample shows that students are less likely to conduct research through the Internet or electronic discovery tools than librarians expected, despite knowledge of those possibilities. Their conclusions prove that in-person and printed scholarly communications remain 
essential references for young Latin Americanists. ${ }^{8}$ While surveys are useful, citation analyses of graduate-level work illustrate actual research usage. An added benefit is that citation studies are unobtrusive means for assessing what scholars use in their arguments.

A few citation studies address Latin American topics and varying resource formats from specific disciplines, but they do not extend analyses across academic departments. Meiyolet Méndez and Karen Chapman, for example, address Latin American history citations in the Hispanic American Historical Review. Their findings underscore the importance of monograph and foreign language materials in Latin American history. ${ }^{9}$ David S. Nolen confirms the importance of the monograph in literature as well. He finds that, despite some preference for English-language sources in Latin American literature, a broad presence of Spanish-language materials remains constant from 1970 to 2000. For Spanish-language citations, he finds - with some nuance from Mexico and Argentina-increased references to scholarly monographs and collected essays, with a shift in citations from monographs to collected essays. In contrast, for English-language materials, the shift favors monographs over collected essays. ${ }^{10}$

Brazilian scholars Ana Maria Mattos and Eduardo José Wense Dias argue that citation analyses of academic dissertations can inform decision-making processes. ${ }^{11}$ Nonetheless, examinations of graduate student citations across classifications from which area studies draw, like the humanities and social sciences, are conspicuously absent from library literature. Anne Buchanan and Jean-Pierre V.M. Herubel's small and limited sample of political science and philosophy dissertations stands out as one attempt to examine citations in graduate work from the social sciences and the humanities. This work suggests that philosophy or humanities students are likely to cite monographs and older materials, while political science or social science students favor more recent journal articles and government documents. ${ }^{12}$ It reaffirms assumptions about the types of materials scholars in the humanities and social sciences tend to prefer, namely books in the humanities and articles in the social sciences.

Despite the vast literature in citation studies, it is rare to find nuanced analyses across disciplines. Jennifer E. Knievel and Charlene Kellsey's analysis of citations in key journals from eight humanities disciplines is the most recent and noteworthy example. Their assessment of notable usage provides a benchmark for this article. Their work also presents comparative data on language and format preferences in art, classics, history, linguistics, literature, music, philosophy, and religion. It demonstrates quite clearly that collective data can often misguide librarians because references to English-language monographs do predominate but percentages of foreign language usage vary considerably from discipline to discipline. In art, for example, Knievel and Kellsey find far greater-than-average reliance on foreign language monographs, while in philosophy they note heavy reliance on English-language sources. ${ }^{13}$ There is no single assumption that fits all humanities disciplines.

The aforementioned citation studies analyze limited samples, and they are narrow in scope. This article incorporates a broad disciplinary sample of dissertations from all departments offering doctoral degrees at UNM. While PhD students in these fields typically employ sources published in the United States by American scholars and Latin American scholars writing in English, they also use sources from the countries they study, generally written in Spanish or Portuguese. These foreign language resources are the primary concern in this article.

\section{Methodology: Data Set \#1, Spanish- and Portuguese-Language Citations across PhD- Granting Departments}

This study begins with a large sample that is necessarily unexceptional, not driven by 
particularly active or inactive cycles in faculty availability or in institutional motivations or a particular country. It examines a full decade of dissertations to prohibit anomalies from corrupting a cross-section of a generation of scholars. It considers all dissertations at UNM-again, to avoid altering results. With an average of 200 dissertations annually, this process is labor-intensive and it requires analytical subjectivity for the selection process. The benefit is that it does not target any specific department-leaving the data open for unexpected discoveries.

A perusal of dissertation bindery lists from January 2000 through December 2009 identified 550 titles - a little over a quarter of the total dissertation output during this decade-containing words identifying possible Latin American names, places, or events, as determined by the Latin American Collections Curator and a Latin American Studies library fellow. From that list, the fellow searched UNM's online catalog to obtain abstracts and keywords from each of these 550 dissertations. Works addressing contemporary New Mexico and Hispanic, Latino, or Chicano topics in the United States fell outside the scope of Latin American studies and were eliminated as a result. This left 182 dissertations in the sample. To protect the anonymity of the authors, this sample excluded dissertations from departments with only one title on Latin America, leaving a total of 179.

This article consequently analyzes citations from dissertations granted by 17 academic departments: American Studies; Anthropology; Art History; Biology; Communication; Economics; Educational Thought and Social Studies; English; Health, Physical Education and Recreation; History; Language Literacy and Socio-Cultural Studies; Latin American Studies; Political Science; Psychology; Romance Languages; Sociology; and the Department of Spanish and Portuguese. ${ }^{14}$ Some of these departments are in the social sciences, while others are in the humanities. A few originate from the sciences, while others are inherently multi- or interdisciplinary.

This sample demonstrates that the departments most attentive to Latin America at UNM in terms of the number of dissertations are Anthropology (31 dissertations), History (21 dissertations), and the Department of Spanish and Portuguese (28 dissertations). The departments least focused are Sociology and English (3 dissertations each), Economics (4 dissertations), Romance Languages and Art History (5 dissertations each).

The 179-dissertation sample includes the following information: year of graduation, PhD-granting department, and a total number of bibliographic citations organized into multiple categories broken down by language (Spanish, Portuguese, and English) and by type: books, articles, and chapters in books (considered here as book citations). Spanish- and Portuguese-language books and articles published in Latin America are the focus of the study because of the library's emphasis on acquisitions in this area. Additional categories not addressed in this article included European-published texts, general references or encyclopedic sources, newspapers, government reports, papers presented at conferences, theses and dissertations, archival sources, database reports or lists, websites, images, films, or other creative works.

\section{Results and Discussion: Data Set \#1, Spanish and Portuguese-Language Citations across PhD-Granting Departments}

The 179 dissertations contain 26,483 citations, of which 16,981 (64\%) refer to books and/ or chapters in books and 9,532 (36\%) to journal articles. Citations of English-language materials predominate with 22,511 (85\%). Spanish-language citations are significant, however, at 14 percent. Portuguese comes in with just under 1 percent. While few scholars define exactly what constitutes significant foreign language usage, Knievel and Kellsey set some parameters. In their estimation, 11.1 percent is "extraordinary" while 5 to 8 percent is dominant, and anything under 2 percent is minimal. ${ }^{15}$ These 
designations imply that anything between 2 and 5 percent is noteworthy. Based on these estimations, at UNM, Spanish-language usage is substantial; and, in a couple of academic departments, Portuguese usage is notable.

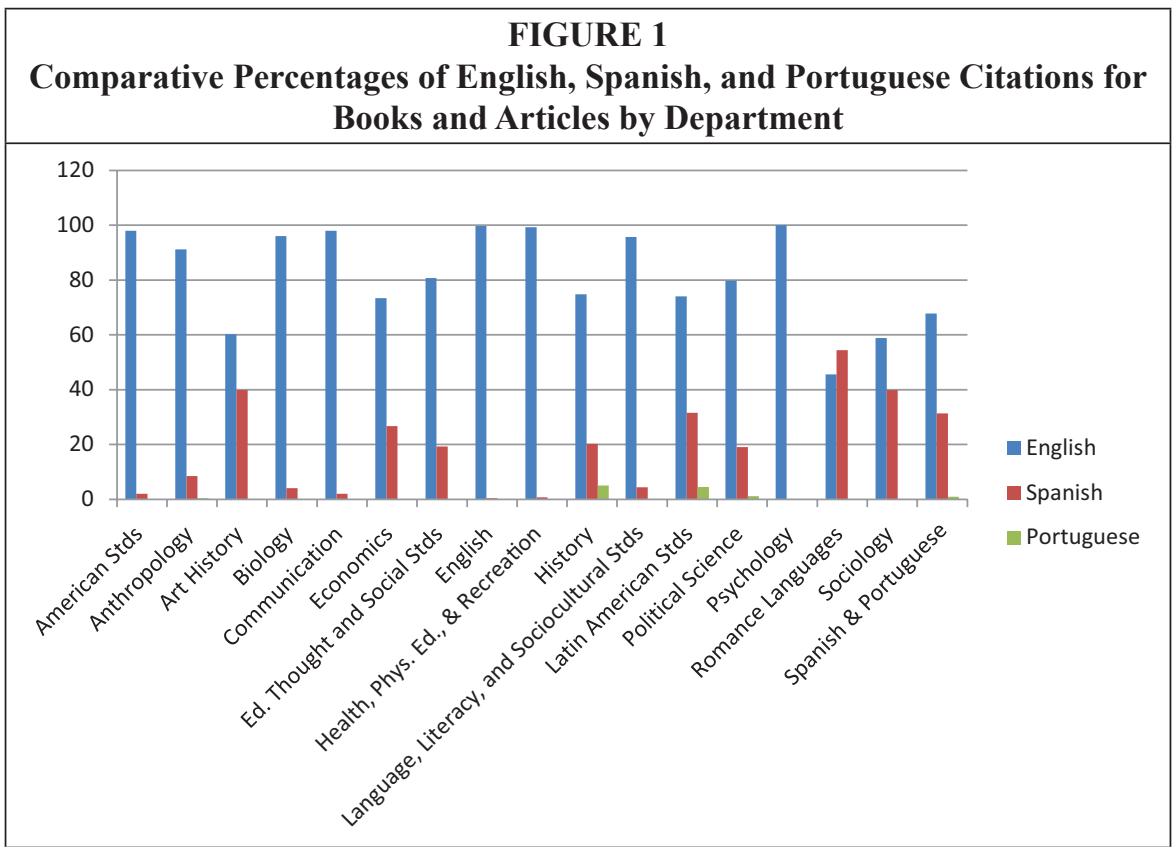

\section{Spanish-Language Book Usage}

Book citations in Spanish illustrate extraordinary usage at UNM, well above Knievel and Kellsey's 11 percent. This sample includes 2,697 Spanish-language book citations, 16 percent of the total book citations in all languages. The highest raw numbers for Spanish-language book usage appear in History (512 citations), the Department of Spanish and Portuguese (488 citations), Anthropology (353 citations), Art History (276 citations), and Political Science (273 citations). They clearly justify continued support for acquisitions in these fields and demonstrate a strong contribution to research across social science and humanities disciplines.

Raw numbers do not tell the whole story, however. If one looks at percentages by comparing the number of citations to the number of dissertations in a given department, a different picture emerges quickly. For example, History, with 512 citations, approved 21 dissertations (averaging 20 percent Spanish-language book citations), while Art History, with 276 citations, approved five dissertations (averaging 40 percent Spanish-language book citations). Percentages identify additional departments in which Spanish-language books are prominent in the research process. The highest percentages of book citations come from Romance Languages (54 percent), Art History (40 percent), Sociology (39 percent), Latin American Studies (32 percent) and the Department of Spanish and Portuguese (31 percent). Even though these departments produced fewer dissertations than others in the sample, they have the highest rate of citations-justifying collection development priorities in these disciplines.

The high percentage in Romance Languages - which, at UNM, oddly includes French and Italian but excludes Spanish - is a surprise, perhaps because the majority of the 


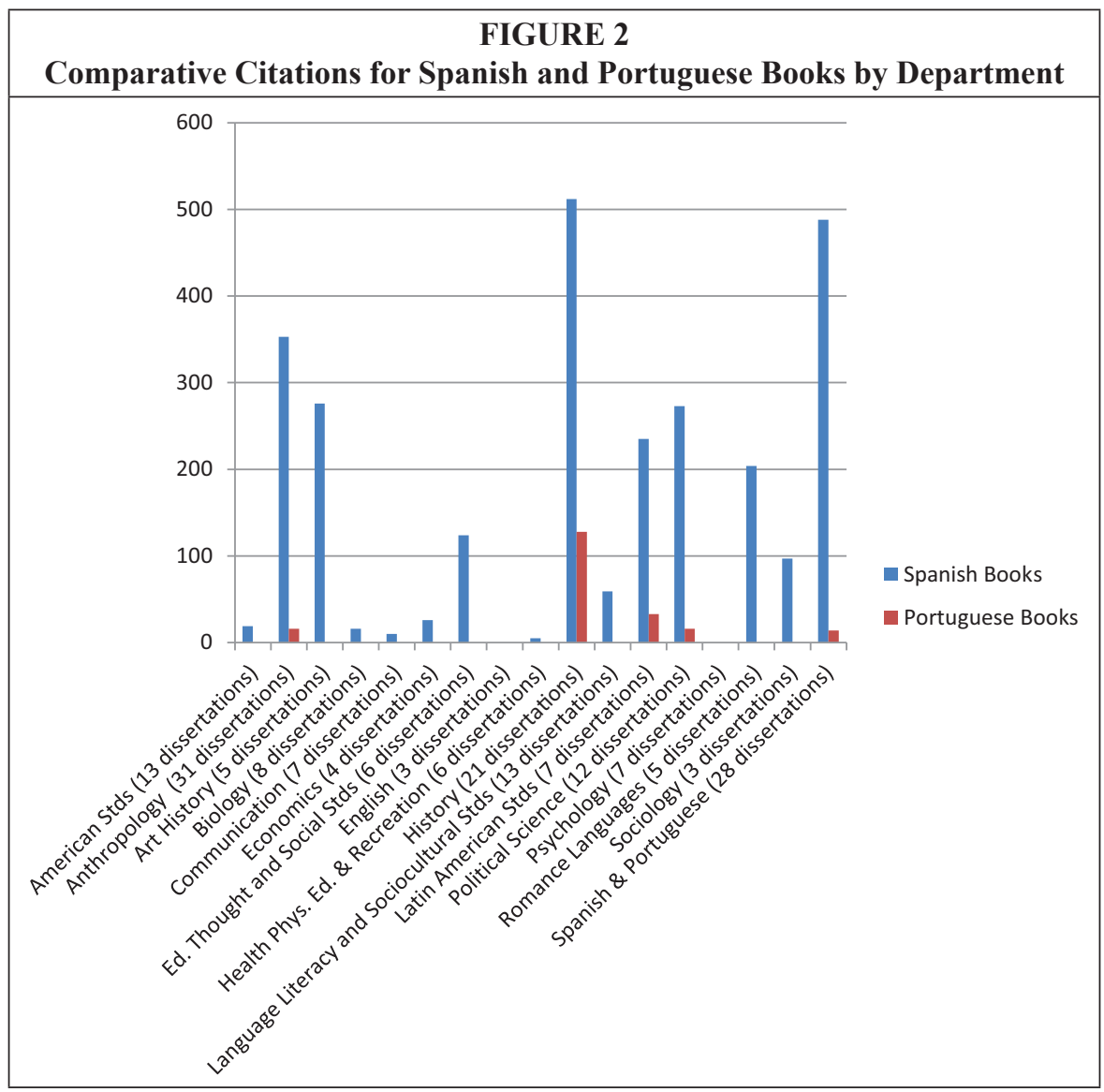

dissertations in this 10-year sample refer to linguistic theory written in or translated into Spanish. High raw numbers and percentages in Art History are not surprising. In addition to bearing out Knievel and Kellsey's findings, they reflect a long-term collection development priority at UNM in this discipline. The heavy usage of Spanish-language books in Sociology is unexpected but perhaps explained by citations of local Latin American case studies, more readily published in the region than in the United States.

The raw number for Latin American Studies (235 citations) is just under half that in the Department of Spanish and Portuguese (488 citations). However, the former generated these citations in seven as opposed to 28 dissertations. The average number of Spanish-language book citations per dissertation in Latin American Studies doubles that of the Department of Spanish and Portuguese (34 versus 17). While some would expect students studying foreign languages to cite foreign language materials more readily, this study indicates that students addressing Latin America from interdisciplinary perspectives have the language skills and confidence to consult foreign language materials in their research. Two other departments, History and Political Science, have consistently high raw numbers, and their percentages for the use of Spanish-language book citations seem constant at 20 percent for each dissertation.

While most citation studies suggest that social science disciplines favor journal articles over books, they do not consider this preference when addressing foreign language sources. These data illustrate a preference for English-language journals 
over English-language books. When the language changes to Spanish, however, so does the inclination to prioritize articles: Spanish-language books are more cited than Spanish-language journals. In Economics, 27 percent Spanish-language book citations outweigh 4 percent article citations. The same holds true in Anthropology, Biology, Political Science, and Sociology, where books in Spanish are more often cited on average than articles in Spanish. These data bear out what Mazurkiewicz and Potts find in terms of Latin Americanist student research behavior and book usage. Even given the availability of database discovery tools at UNM, these social science students used more Spanish-language books on average than articles. Conversely, and also in opposition to general assumptions on humanist preferences for books, these data reveal greater percentages in Spanish-language article over book citations. These findings indicate that the discovery tools for articles and books are equally good.

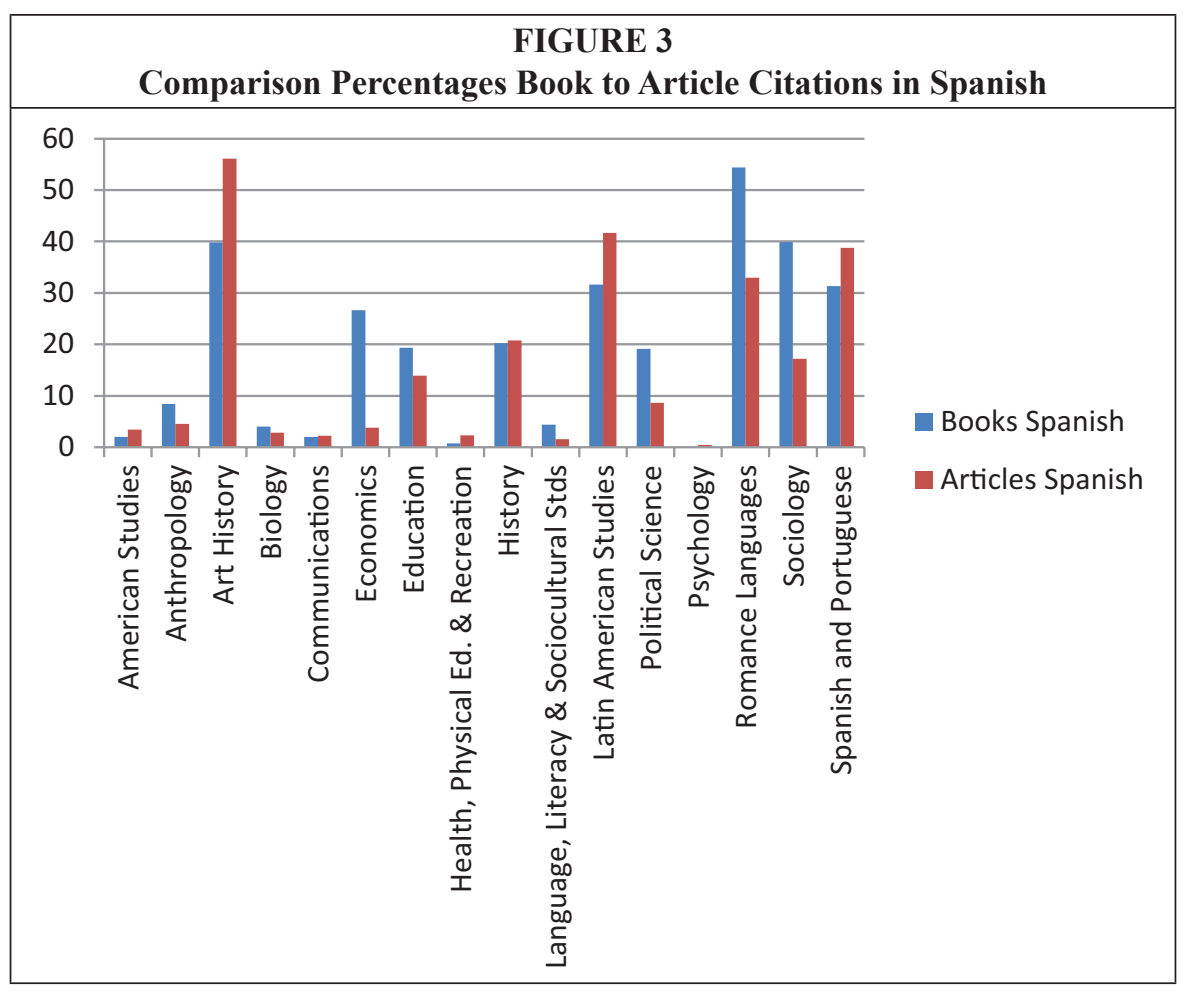

\section{Portuguese-Language Book Usage}

Dissertations from five departments - History, Latin American Studies, Anthropology, Political Science, and the Department of Spanish and Portuguese-include Portugueselanguage book citations. Since the Department of Spanish and Portuguese does not offer a PhD in Portuguese, the numbers from this department are minimal. Book citations in Portuguese illustrate limited usage. This sample includes 207 Portuguese-language book citations, or 0.7 percent of the total book citations in all languages. The highest raw numbers for Portuguese- language books appear in History (128 citations), Latin American Studies (33 citations), Political Science and Anthropology (16 citations each) and the Department of Spanish and Portuguese (14 citations). The highest percentages come from History (5 percent) and Latin American Studies (4 percent). The percentage 
is minimal in the other three departments, at less than 1 percent. Portuguese citations are coming from only two or three dissertations in these disciplines. These low numbers suggest that few people have Portuguese-language skills and current collection development should focus on building Portuguese-language literacy. While the overall percentage is minimal, History and Latin American Studies show promise. The focus on history in Portuguese-language purchases seems warranted, but outreach efforts to promote these resources should be enhanced. The second emphasis on Brazilian language and literature supports the curriculum through the master's level.

\section{Spanish-Language Journal Article Usage}

Article citations in Spanish vary across departments, but they still reflect significant raw numbers and percentages. A total of 1,103 Spanish articles amounted to 12 percent of the articles cited in this sample. In raw numbers, the highest usage comes from the Department of Spanish and Portuguese (316 citations), History (173 citations), Anthropology (162 citations), and Art History and Latin American Studies (120 citations each). These numbers show that humanists can find and cite Spanish-language journals and that journal and database acquisition is justified in these disciplines.

In percentages, Art History at 56 percent comes out on top, followed by Latin American Studies (42\%), the Department of Spanish and Portuguese (39\%), Romance Languages (33\%), and History (21\%). Art History is noteworthy because Spanishlanguage articles actually outweigh English articles with a percentage split of 56 to 44. An analysis of recent articles in Art Bulletin, the journal examined by Knievel and Kellsey, is illustrative of this bias. Of the 17 articles published in Art Bulletin in 2011,

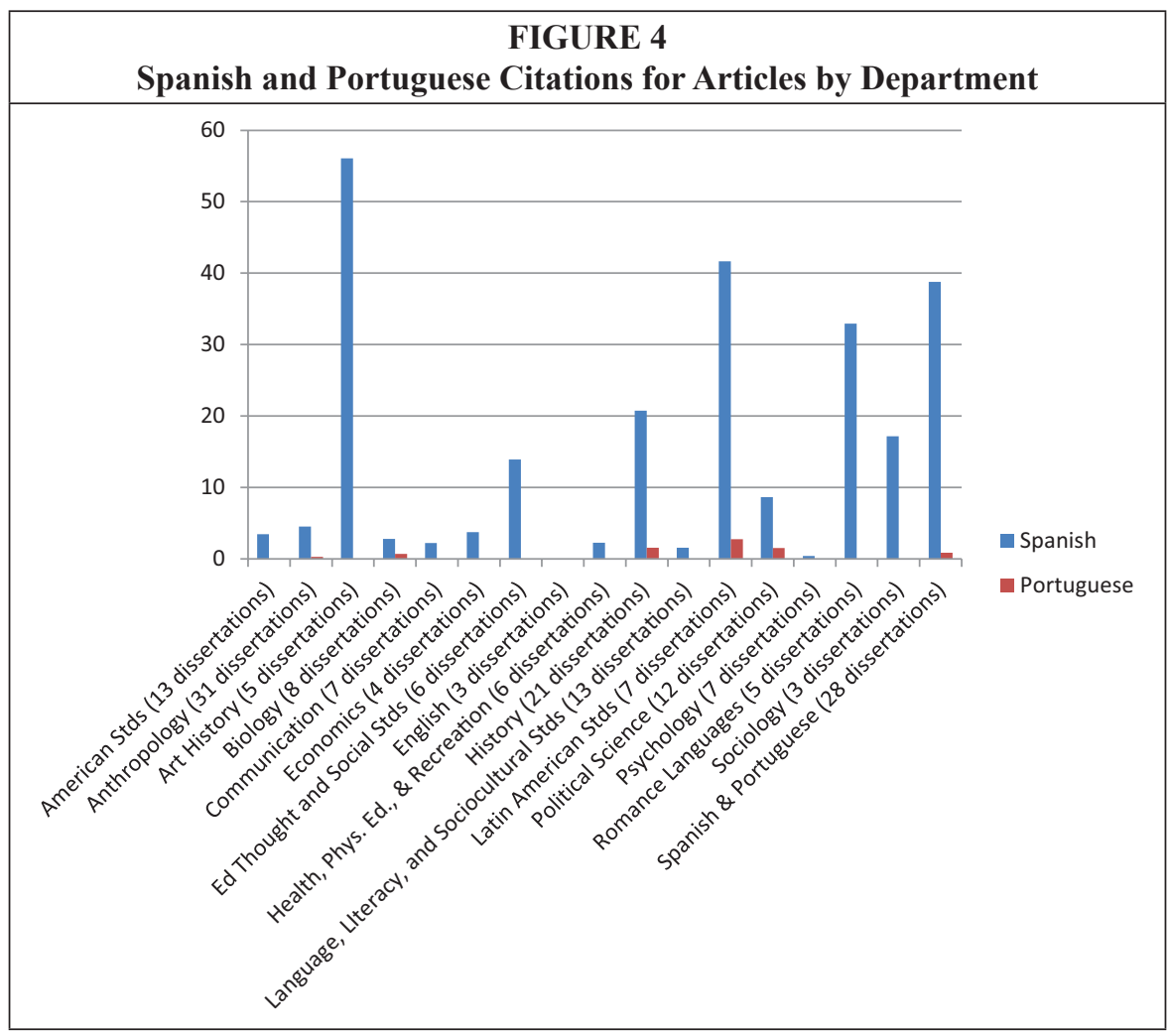


11 deal exclusively with European topics. Three examine Asian art and three address American examples. Only one of these final three reflects on art in a Latin American country. ${ }^{16}$ Latin Americanist art historians look more readily at Spanish-language articles because of the absence of such publications in English-language journals, underscoring the continued necessity for the acquisition of Latin American journals in this discipline.

\section{Portuguese-Language Journal Article Usage}

Dissertations from six departments-History, Latin American Studies, Political Science, Anthropology, the Department of Spanish and Portuguese, and Biology -include Portuguese article citations. In raw numbers and percentages, these numbers again illustrate negligible usage with only 48 combined article citations ( 0.5 percent) of the articles in this sample. The highest raw numbers for Portuguese-language articles appear in History (13 citations), Anthropology (10 citations), Latin American Studies (8 citations), the Department of Spanish and Portuguese (7 citations), and Political Science and Biology (5 citations each). These numbers suggest that an investment in Portuguese-language journals is not necessary.

\section{Methodology: Data Set \#2, Mexico}

Unlike Data Set \#1, which only analyzes the research usage of Latin American materials, Data Set \#2 checks this usage against UNM's collections. This second study determines how the library's holdings meet the needs of graduate students. Since a third of the Latin American purchases come from Mexico, this sample isolates dissertations examining Mexico. As in the larger context, this smaller sample represents a full decade of dissertations from a cross-section of a generation of scholars in different disciplines. Of the 179 Latin American dissertations, 40 deal specifically with Mexico. This study further refines this list of 40 geographically specific texts by keeping only those departments that have two or more dissertations on the list (again to protect the anonymity of the scholars), leaving 33 dissertations. The numbers in this smaller sample corroborate many of the findings in the larger one. However, minor differences in percentages favor more Spanish-language citations in these dissertations. This difference reflects a strong institutional emphasis on Mexico.

These dissertations come from the following nine PhD-granting departments: Anthropology (9 dissertations); Art History (3 dissertations); Biology (2 dissertations); Educational Thought and Social Studies (2 dissertations); History (6 dissertations); Latin American Studies (2 dissertations); Political Science (5 dissertations); Sociology (2 dissertations); and Spanish and Portuguese (2 dissertations). As in the larger sample, this one includes dissertations from the social sciences, the humanities, and the sciences, as well as the inherently interdisciplinary program of Latin American Studies. This sample examines the local availability of the cited Spanish-language books and articles per discipline.

For books, this study searches the citations in the local online catalog. When not found there, it identifies titles and authors in WorldCat to elucidate the citation. In cases where the citation was misleading, the union catalog is used to identify the accurate title. For articles, this study searches the journal title in the local online catalog for holdings. If the catalog indicates no holdings, we search titles in local databases.

\section{Results and Discussion: Data Set \#2, Mexico}

The 33 dissertations contain 936 citations, of which 646 (69\%) refer to books and 290 (31\%) to journal articles. Of the 646 book citations, the library holds 73 percent, making the vast majority accessible locally to UNM students. Of the books not available locally, 
14 percent were in WorldCat and 13 percent had no discernible online records anywhere. This could reflect books found in Mexican libraries not participating in WorldCat or inaccurate citations. The library's Mexican holdings without a doubt support graduate research and have a broad impact on the research mission of the university.

Looking at usage by individual department is more useful for collection assessment, however, because it shows where the library has succeeded and where it needs to improve. Several departments meet or exceed the average of the locally available 73 percent, with History at 90 percent, Anthropology at 76 percent, Art History at 74 percent, and Political Science at 73 percent. Sociology is not far behind at 71 percent local availability. Considering that two thirds of these titles appear in only one citation, these percentages reflect broad and diverse usage of comprehensive collections.

This snapshot demonstrates that building Spanish- and Portuguese-language collections has paid off at UNM, but there is still work to do. For Latin American Studies, the library holds only 65 percent of the titles cited, and in the Spanish and Portuguese Department, the library holds a mere 51 percent. Clearly, local library resources serve students in these departments less effectively. In Latin American Studies, students engage in research across disciplines, making it more difficult for the subject librarian to predict their research needs when building the collection. In the Spanish and Portuguese Department, PhD students tend to focus on a literary genre or a specific author or group of authors - often obscure or not yet established. Though not in place during the decade from which this sample comes, current Purchase on Demand policies and well-established connections between these students and Spanish-language selectors address this challenge.

The 290 journal article citations come from 46 journals, of which the library holds 30. Clearly, some review of the journals not available is in order to consider additional subscriptions. Undoubtedly, UNM library holdings support research on Mexico quite well. Because of UNM's focus on Mexico, this sample may reflect greater availability of Spanish-language resources than those of other Latin American countries.

\section{Other Relevant Factors}

Additional parameters may explain high Spanish-language citation rates. Scholarly communication occurs through face-to-face contact as well as through bibliographic interactions; and the two tend to work interchangeably. PhD students researching in Latin America have been among those best-funded through the LAII as a result of title VI NRC funding, and the Spanish program recruits native speakers to double as instructors. Bilingualism in New Mexico is likely relevant as well. This pedagogically charged environment, replete with native and non-native speakers, as well as research abroad, facilitates personal relations that result in higher levels of resource and reference sharing. The samples presented in this article prove that providing access to books and articles can be an effective means for enhancing scholarly communications. However, invigorating the teaching environment with native speakers and encouraging students to build scholarly networks through research and travel are complementary, putting reduced Title VI NRC funds to good use.

The library has embraced outreach as a means for enhancing information literacy and collection development, in the face of diminished staffing. While not applicable to the time period reflected in these samples, instruction and collections outreach initiatives described elsewhere invite students into library spaces to exhibit and present their academic work while welcoming them to engage with special collections. ${ }^{17}$ Working locally through bibliometrics and face-to-face references enables library staff and faculty to identify lacunae. While systematic bibliometrics identify specific titles for collection development, fostering in-person scholarly networking has been 
productive recently, especially for targeted titles in less canonic literature and more popular arts. These interactions have also prompted Latin American Studies to invite the Hispanic and Latin American Collections Curator to develop and teach a capstone course in Latin American Studies and to collaborate with Latin Americanist faculty in the social sciences and humanities to structure a graduate-level methods course. Direct integration of library collections into the classroom enhances information literacy on Latin American resources as well as critical discussions of building a national capacity in the area of foreign language and global resources.

\section{Conclusion}

When considered carefully within local contexts, analysis of secondary source citations reveals important information for collection development. Basic bibliometrics identify connections between $17 \mathrm{PhD}$-granting departments at UNM and Spanish- and Portuguese-language collections in the library. When taken in sum, these data reflect broad usage and substantiate the expenditures on Latin American books and journals. Spanish-language citations are much higher than the benchmarks determined by Knievel and Kellsey. This exceptional usage indicates that Spanish-language sources especially are essential to the research mission at UNM. This prominence extends beyond the local community and draws outside researchers as well through LAMP, LARRP, and GWLA.

The first data set indicates that raw numbers and percentages reveal different strengths and weaknesses, which are important for collection development. Raw numbers help identify those departments that produce notable foreign language citations - History, Spanish and Portuguese, and Anthropology - while percentages highlight more intensive usage in other departments-Romance Languages, Art History, and Sociology. These data produced some surprises. They revealed one anomaly - the high usage of Spanish-language materials by students of French and Italian. Another surprise is the higher usage of Spanish-language articles over English-language articles in Art History and the higher usage of Spanish-language books than journals in the social sciences. These discoveries underscore that general citation studies do not always reflect the idiosyncrasies of Foreign Language and Area Studies. Data for Portuguese show that, with the exception of Brazilian history books, there was minimal usage of Portuguese-language sources at UNM. Locally, collection priorities need to be reviewed with a shift from research level to language literacy materials. The second data set on Mexico shows that the local collection supports the research needs of PhD students, especially for books. However, the journal collection could be increased.

As a broader analysis for area studies librarianship, these studies prove that preconceived ideas about foreign language usage from general citation studies do not provide a reliable template, specifically for books and journals. Librarians need to look at their local research community and their usage habits and should not rely on general studies for answers. Only in-depth analyses of the research interests of local scholars can yield useful data for acquisitions. Research libraries are complex organisms serving multiple communities with varying research requirements. Often the simplistic use of data for expedient solutions bypasses a thorough analysis. In the process, informed decisions on research-level collections take second fiddle to daily operational priorities. This attitude enables reactionary decisions for short-term and often overly simplified solutions rather than advancing thoughtful, proactive strategies. The challenge is to use the complexity of local data as a point of departure for a discussion on data-driven collection development, one that reinserts library collections as research laboratories into the college and research library conversation. 


\section{Acknowledgements}

We thank the Latin American and Iberian Institute as well as the Research Allocations Committee at the University of New Mexico for funding elements of this research. Questions, comments, and suggestions from the Editor at College and Research Libraries and several reviewers have challenged us to express the complexity of area studies more clearly, and we are grateful for the experience.

\section{Notes}

1. James F. Zimmerman cited by Russ Davidson, Latin American Holdings in the University of New Mexico Library: An Illustrated History and Guide (Albuquerque: University of New Mexico Press, 2004): 8.

2. Dan C. Hazen, "The Latin Americanist Research Resources Project: A New Direction for Monographic Cooperation?" ARL Bimonthly Report 191 (1997): 1-6; Dan C. Hazen, “Dancing with Elephants: International Cooperation in an Interdependent (but Unequal) World," Collection Management 24, no. 3/4 (1999): 185-213.

3. Library Statistics for Latin American Collections 2010-2011," ed. Sarah Buck Kachaluba, Seminar on the Acquisition of Latin American Library Materials, available online at http://salalm.org/ collection-development-resources/institutional-information/latin-american-collections/ [accessed 16 January 2014].

4. Lewis Hanke, "The Development of Latin-American Studies in the United States, 19391945," The Americas 4, no. 1 (1947): 32-64; see also Helen Delpar, Looking South: The Evolution of Latin Americanist Scholarship in the United States, 1850-1975 (Tuscaloosa: University of Alabama Press, 2008) and Paul W. Drake and Lisa Hilbink, "Latin American Studies: Theory and Practice," in The Politics of Knowledge, ed. David L. Szanton (Berkeley: University of California Press, 2004): $1-27$.

5. Alan Tansman cited by David L. Szanton, "Introduction," in The Politics of Knowledge (2004): 1.

6. Lynn Shirey, "Latin American Collections," in Building Area Studies Collections (2007): $108-30$.

7. Building Area Studies Collections, eds. Dan C. Hazen and James H. Spohrer (Wiesbaden, Germany: Harrassowitz, 2007).

8. Orchid Mazurkiewicz and Claude H. Potts, "Researching Latin America: A Survey of How the New Generation Is Doing Its Research," Latin American Research Review 42, no. 3 (2007): 161-82.

9. Meiyolet Méndez and Karen Chapman, "The Use of Scholarly Monographs in the Journal Literature of Latin American History," Electronic Journal of Academic and Special Librarianship 7, no. 3 (2006), available online at http://southernlibrarianship.icaap.org/content/v07n03/mendez_m01. $\mathrm{htm}$ [accessed 16 January 2014].

10. David S. Nolen, "Characteristics of La Literatura: A Reference Study of Latin American Literature," College and Research Libraries 71, no. 1 (2010): 9-19; David S. Nolen, "Publication and Language Trends of References in Spanish and Latin American Literature," College and Research Libraries 75, no. 1 (2014): 34-50, available online at http://crl.acrl.org/content/75/1/34.full.pdf+html [accessed 16 January 2014].

11. Ana Maria Mattos and Eduardo José Wense Dias, “Desenvolvimento de coleções em bibliotecas universitárias: uma abordagem quantitativa," Perspectivas em Ciência da Informação 14, no. 3 (2009): 1-23, available online at www.scielo.br/pdf/pci/v14n3/04.pdf [accessed 16 January 2014].

12. Anne Buchanan and Jean-Pierre V.M. Herubel, "Comparing Materials Used in Philosophy and Political Science Dissertations: A Technical Note," Behavioral \& Social Sciences Librarian 12, no. 2 (1993): 63-70.

13. Jennifer E. Knievel and Charlene Kellsey, "Citation Analysis for Collection Development: A Comparative Study of Eight Humanities Fields," Library Quarterly 75, no. 2 (2005): 142-68; Jennifer E. Knievel and Charlene Kellsey, "Global English in the Humanities? A Longitudinal Citation Study of Foreign-language Use by Humanities Scholars," College E Research Libraries 65, no. 3 (2004): 194-204, available online at http://crl.acrl.org/content/65/3/194.full.pdf+html [accessed 16 January 2014].

14. At UNM, the Spanish and Portuguese Department is separate from the Romance Languages Department, which entails French and Italian.

15. Knievel and Kellsey, "Citation Analysis for Collection Development," 142-48.

16. These articles include the following: Fabio Barry, "The Mouth of Truth and the Forum 
Boarium: Oceanus, Hercules, and Hadrian," Art Bulletin 93, no. 1 (2011): 7-37; Robert H. Sharf, "The Buddha's Finger Bones at Famensi and the Art of Chinese Esoteric Buddhism," Art Bulletin 93, no. 1 (2011): 38-59; Jeehee Hong, "Theatricalizing Death and Society in the Skeletons' Illusory Performance by Li Song," Art Bulletin, 93, no. 1 (2011): 60-78; Eleanor Moseman, "At the Intersection: Kirchner, Kubišta, and Modern Morality, 1911-14," Art Bulletin 93, no. 1 (2011): 79-100; Margaret A. Sullivan, "Bruegel the Elder, Pieter Aertsen, and the Beginnings of Genre," Art Bulletin 93, no. 2 (2011): 127-49; Anne L. Schroder, "Fragonard's Later Career: The Contes et Nouvelles and the Progress of Love Revisited," Art Bulletin 93, no. 2 (2011): 150-77; Jason Gaiger, "Hegel's Contested Legacy: Rethinking the Relation between Art History and Philosophy," Art Bulletin 93, no. 2 (2011): 178-94; André Dombrowski, "History, Memory, and Instantaneity in Edgar Degas's Place de la Concorde," Art Bulletin 93, no. 2 (2011): 195-219; Robert Lifkin, "Philip Guston's Return to Figuration and the '1930s Renaissance' of the 1960s," Art Bulletin 93, no. 2 (2011): 220-42; Rebecca Molholt, "Roman Labyrinth Mosaics and the Experience of Motion," Art Bulletin 93, no. 3 (2011): 287-30; Joost Keizer, "Michelangelo, Drawing, and the Subject of Art," Art Bulletin, 9, no. 3 (2011): 304-24; Amy Freund, "The Citoyenne Tallien: Women, Politics, and Portraiture during the French Revolution," Art Bulletin 9, no. 3 (2011): 325-44; Michael Lobel, "John Sloan: Figuring the Painter in the Crowd," Art Bulletin 93, no. 3 (2011): 345-68; Conrad Rudolp, "Inventing the Exegetical Stained-Glass Window: Suger, Hugh, and a New Elite Art," Art Bulletin 93, no. 4 (2011): 399-422; Livia Stoenescu, "Ancient Prototypes Reinstantiated: Zuccari's Encounter of Christ and Veronica of 1594," Art Bulletin 93, no. 4 (2011): 423-48; James M. Cordova, "Clad in Flowers: Indigenous Arts and Knowledge in Colonial Mexican Convents," Art Bulletin 93, no. 4 (2011): 449-67; and Christine M.E. Guth, "Hokusai's Great Waves in Nineteenth-Century Japanese Visual Culture," Art Bulletin 9, no. 4 (2011): 468-85.

17. Suzanne M. Schadl, Molly Nelson, and Kristen S. Valencia, “Uncommons: Transforming Dusty Reading Rooms into Artefactual, 'Third Space' Library Learning Labs," (forthcoming) in Journal of Learning Spaces 4, no. 1 (2015); Suzanne M. Schadl and Claire-Lise Bénaud, "Exhibiting Comics and Caricatures: Expanding Visual Literacy from the Reading Room to Special Collections," SALALM \#57 Preserving Memory: Documenting and Archiving Latin American Popular Culture, ed. Lynn Shirey (New Orleans: SALALM Secretariat, 2014), 65-74. 